\title{
Peak Oil: Testing Hubbert's curve via theoretical modeling
}

\author{
S. H. Mohr • G. M. Evans
}

Received: date / Accepted: date

5 Abstract A theoretical model of conventional oil production has been developed. In partic-

6 ular the model does not assume Hubbert's bell curve, an asymmetric bell curve or an R/P 7 method is correct, and does not use oil production data as an input. The theoretical model is 8 in close agreement with actual production data until the 1979 oil crisis with an $R^{2}$ value of 9 greater than 0.98 in all three scenarios. Whilst the theoretical model indicates that an ideal o production curve is slightly asymmetric, which contradicts Hubbert's curve, the ideal model 1 compares well with the Hubbert model with $R^{2}$ values of greater than 0.95 . Amending the 12 theoretical model to take into account the 1979 oil crisis, and assuming a URR in the range 13 of 2-3 trillion barrels, the amended model predicts conventional oil production to peak be14 tween 2010 and 2025. The amended model for the case when the URR is 2.2 trillion barrels 15 indicates that oil production peaks in 2013.

Keywords Peak Oil $\cdot$ Modeling $\cdot$ Hubbert's Curve

\footnotetext{
S. H. Mohr

University of Newcastle, Faculty of Engineering and Built Environment, Chemical Engineering, University Drive, Callaghan, NSW 2308, Australia

Tel.: +612-49528065

E-mail: steve.mohr@studentmail.newcastle.edu.au

G. M. Evans

University of Newcastle, Faculty of Engineering and Built Environment, Chemical Engineering, University Drive, Callaghan, NSW 2308, Australia

Tel.: +612-49215897

E-mail: Geoffrey.Evans@newcastle.edu.au
} 
1 Introduction

2 There is considerable debate on when and how steeply oil production will peak, with a 3 range of estimate from 2004 to 2047 e.g. ASPO (2004); Deffeyes (2002); Bakhtiari (2004); 4 Mohr and Evans (2007); Wells (2005a,b); EIA (2004). The considerable range in peak oil estimates is due to two main reasons. The first problem is uncertainty in conventional oil URR, with Bauquis (2003) indicating that estimates range from 2 to 3 trillion barrels. The second reason is the different methods for modeling conventional oil production. It should be noted that oil production is model in three distinct ways. Wells (2005a,b); Mohr and Evans (2007); Deffeyes (2002) used a bell (or Hubbert) curve to model oil production. The second method, which was used by ASPO (2004); Bakhtiari (2004), was a graphical model with limited data as to how the model is created. The last method, which was used by EIA 12 (2004) assumed oil production declines with a R/P ratio of 10 . The different models create 13 very different production profiles, and hence a wide range of predictions, which ultimately 14 confuse the wider community. Rather than assume a production curve, and attempt to justify 15 its use, this article will endevour to generate a model based on theory. With the theory explained, we will then determine what the oil production profile looks like.

\section{Review of Literature}

Before explaining how the current model works, it is important to look carefully at the theoretical models already developed by Reynolds (1999); Bardi (2005). Reynolds (1999)

(2005) using this technique explains the model mathematically as:

$$
p(t)=k(t) \frac{U R R-C_{d}(t)}{U R R},
$$

where $p(t)$ is the expected discovery percentage, $U R R$ is the Ultimate Recoverable Resources (TL), $C_{d}(t)$ is the cumulative discoveries (TL), and $k(t)$ is the technology function, which is quoted from Bardi (2005) as "a simple linear function of the amount of previously found [oil reserves] that starts at 1 and increases proportionally to the total amount of found 
1 [oil reserves]". The models of Reynolds (1999); Bardi (2005) are based on a simplified

2 scenario with Robinson Crusoe digging for buried hardtacks (food).

The work done by Brandt (2007) is statistical. Brandt (2007) obtained production data

4 for many places of various sizes. The result from Brandt (2007) research is that the rate

5 difference, $\Delta r$, is slightly positive with a median of 0.05 year $^{-1}$, which implies that on

6 average the rate of increase is slightly larger than the rate of decrease Brandt (2007), see

7 Appendix A.

83 Model

3.1 Discoveries:

We will assume that finding oil is equivalent to the mayflower problem, hence the expected discovery percentage function will be determined by Equation 1 (Bardi, 2005). Now the technology function $k(t)$ must be between 0 and 1 , in order for the expected discovery percentage to remain bounded between 0 and 1 . It is worth noting that some Optimists such as Linden (1998) believe that technology makes "marginal hydrocarbon resources" economic. It is also reasonable to assume that the technology function is non-decreasing.

Given these constraints we will assume the technology function $k(t)$ is:

$$
k(t)=\left[\tanh \left(b_{t}\left(t-t_{t}\right)\right)+1\right] / 2,
$$


1 where $b_{t}$ and $t_{t}$ are constants with units (year ${ }^{-1}$ ) and (year) respectively. Hence the expected

2 discovery percentage function is:

$$
p(t)=\left[\tanh \left(b_{t}\left(t-t_{t}\right)\right)+1\right] \frac{U R R-C_{d}(t)}{2 U R R} .
$$

5

6

$$
\frac{d C_{d}(t)}{d t}=\left[\tanh \left(b_{t}\left(t-t_{t}\right)\right)+1\right] \frac{\left(U R R-C_{d}(t)\right)^{2}}{2 U R R} .
$$

14 With the trivial assumption that initially $C_{d}(0)=0$, Equation 4 is solved to get Equation 5

$$
C_{d}(t)=U R R-\frac{2 b_{t} U R R}{2 b_{t}+t b_{t}+\ln \left(\frac{\cosh \left(b_{t}\left(t-t_{t}\right)\right)}{\cosh \left(b_{t} t_{t}\right)}\right)} .
$$


1 Let $y_{d}(t)$ denote the yearly discoveries (TL/year), $d C_{d}(t) / d t$, then by differentiating Equa-

2 tion 5 we obtain,

$$
y_{d}(t)=\frac{2 b_{t}^{2} U R R\left(1+\tanh \left(b_{t}\left(t-t_{t}\right)\right)\right)}{\left(2 b_{t}+t b_{t}+\ln \left(\frac{\cosh \left(b_{t}\left(t-t_{t}\right)\right)}{\cosh \left(b_{t} t_{t}\right)}\right)\right)^{2}} .
$$

reservoir, we have

$$
U R R_{l}=y_{d}\left(t_{l}\right)
$$

\subsection{Reservoir Production:} number of wells built is not $w_{l_{T}}$ but $w_{l_{T_{a c t}}}$ which is defined as

To determine the production curve from a reservoir, we will assume that oil production is related to the number of wells drilled, and the production per well. Let $C_{p_{l}}(t)$ denote the cumulative production from the $l$-th reservoir (TL). Let $w_{l}(t)$ denote the number of wells in operation at time $t$. The function $w_{l}(t)$, will be defined by Equation 7

$$
w_{l}(t)=w_{l_{T}}+\left(1-w_{l_{T}}\right) e^{-k_{w_{l}}\left(\frac{C_{p_{l}}(t)}{U R R_{l}}\right)}, t \geq t_{l}
$$

Where $k_{w_{l}}$ is a proportionality constant and $w_{l_{T}}$ is the total number of wells in operation assuming $C_{p_{l}}(t)$ increases to infinity. Note the boundary condition $C_{p_{l}}\left(t_{l}\right)=0$ which implies $w_{l}\left(t_{l}\right)=1$, hence initially there is only one well built. As cumulative production increases the number of wells exponentially decays upwards from 1 well to $w_{l_{T}}$ wells. Note the total

$$
w_{l_{\text {act }}}=\left\lceil w_{l_{T}}-\left(w_{l_{T}}-1\right) e^{-k_{w_{l}}}\right\rceil .
$$

Lets assume that every well in the $l$-th reservoir extracts a total of $U R R_{l} / w_{l_{T_{a c t}}}$ (TL) of oil. Let the $i$-th well start production in the $t_{l_{i}}$-th year, where $t_{l_{i}}$ is the year such that $\left\lceil w_{l}\left(t_{l_{i}}-1\right)\right\rceil<i \leq\left\lceil w_{l}\left(t_{l_{i}}\right)\right\rceil$ (initially $\left.t_{l_{1}}=t_{l}\right)$. Let $C_{p_{l_{i}}}$ denote the cumulative production from well $i$. Production for an individual well is assumed to be the idealized well explained 
1 in Arps (1945). In this case, there is no water injection, and oil production in the $i$-th well,

$2 P_{l_{i}}$, is proportional to the pressure in the $i$-th well, $\operatorname{Pr}_{l_{i}}$. Further the pressure in the well is

3 proportional to the remaining amount of oil in the $i$-th well, $\left(U R R_{l} / w_{l_{T_{a c t}}}-C_{p_{l_{i}}}\left(t-t_{l_{i}}\right)\right)$,

4 as shown in Equations 8 and 9 (Arps, 1945):

$$
P_{l_{i}}(t)=k_{1_{l_{i}}} \operatorname{Pr}_{l_{i}}(t)
$$

$$
\operatorname{Pr}_{l_{i}}(t)=k_{2_{l_{i}}}\left(U R R_{l} / w_{l_{T_{a c t}}}-C_{p_{l_{i}}}(t)\right)
$$

6 Note $k_{1_{l_{i}}}$ and $k_{2_{l_{i}}}$ are proportionality constants. Equations 8 and 9 can be combined to obtain

$$
P_{l_{i}}(t)=k_{1_{l_{i}}} k_{2_{l_{i}}}\left(U R R_{l} / w_{l_{T_{a c t}}}-C_{p_{l_{i}}}(t)\right)
$$

8 Now, $d C_{p_{l_{i}}}(t) / d t=P_{l_{i}}(t)$, hence

$$
\frac{d C_{p_{l_{i}}}(t)}{d t}=k_{p_{l_{i}}}\left(U R R_{l} / w_{l_{T_{a c t}}}-C_{p_{l_{i}}}(t)\right)
$$

where $k_{p_{l_{i}}}=k_{1_{l_{i}}} k_{2_{l_{i}}}$, and $C_{p_{l_{i}}}\left(t_{l_{i}}\right)=0$. Now Equation 10 is trivially solved to obtain

$$
C_{p_{l_{i}}}(t)=\frac{U R R_{l}}{w_{l_{T_{a c t}}}}\left[1-e^{-k_{p_{l_{i}}}\left(t-t_{l_{i}}\right)}\right]
$$

10 and differentiating obtains the production curve

$$
P_{l_{i}}(t)=k_{p_{l_{i}}} \frac{U R R_{l}}{w_{l_{T_{a c t}}}} e^{-k_{p_{l_{i}}}\left(t-t_{l_{i}}\right)} .
$$

11 Let the initial production of the $i$-th well, in the $l$-th reservoir be $P_{0_{l_{i}}},\left(P_{l_{i}}\left(t_{l_{i}}\right)=P_{0_{l_{i}}} \forall i\right)$

12 then the production curve for the $i$-th well is (Arps, 1945)

$$
P_{l_{i}}(t)=P_{0_{l_{i}}} e^{-P_{0_{l_{i}}} w_{l} T_{a c t}}\left(t-t_{l_{i}}\right) / U R R_{l} .
$$


Hence the cumulative production for the $l$-th reservoir, $C_{p_{l}}(t)$, is determined iteratively by

2 Equation 11

$$
C_{p_{l}}(t+1)=C_{p_{l}}(t)+\sum_{i=1}^{\left\lceil w_{l}(t)\right\rceil}\left(\frac{P_{l_{i}}(t)+P_{l_{i}}(t+1)}{2}\right),
$$

with the initial condition $C_{p_{l}}\left(t_{l}\right)=0$. The world's cumulative production, $C_{p}(t)$, is trivially

4 the sum of the cumulative production of the reservoirs,

$$
C_{p}(t)=\sum_{l} C_{p_{l}}(t)
$$

5 For ease of use we will assume that all wells in all reservoirs have the same initial production,

$6 P_{0}$, that is $P_{0}=P_{0_{l_{i}}}$, it is also assumed that $k_{w}=k_{w_{l}}$.

\section{Results and Discussion}

Bauquis (2003) indicates that URR estimates for conventional oil have remained constant at 9 between 2-3 trillion barrels (318-477 TL) for the time period of 1973-2000. A Pessimistic case will assume that the $U R R$ is $318 \mathrm{TL}$ ( 2 trillion barrels); the Optimistic case will assume the $U R R$ to be $477 \mathrm{TL}$ ( 3 trillion barrels). An ideal case is also made where the $U R R$ is constants, which need to be defined. For the discovery model we have $U R R, t_{t}$ and $b_{t}$, for the number of wells model its $k_{w}$, and $w_{l_{T}}$ and for the production of a well we need $P_{0}$. The variables for the discovery model were calculated by fitting the model to the actual data from Wells (2005b) using the coefficient of determination, $R^{2}$, for more details see Appendix B. The cumulative discoveries as a function of time is shown in Figure 1.

In order to determine valid estimates for $k_{w}, w_{l_{T}}$, and $P_{0}$, it was necessary to find some literature data. The best literature found to date is from EIA (2007), which has incomplete well and production data for all U.S. states. By analyzing the EIA (2007) data, we assumed $P_{0}=18.3 \mathrm{ML} /$ year, $k_{w}=10.7$ and $w_{l_{T}}=0.072 U R R_{l} / P_{0}$ respectively, for more details 3 see Appendix C. With the constants determined the world model is shown in Figure 2; 
1 and compared to actual production data from BP (2006); DeGolyer and MacNaughton Inc.

2 (2006); CAPP (2006); Williams (2003); Moritis (2005).

The resulting model of production matches the production data with a reasonable precision up to the 1979 oil crisis (year 119 in Figure 2) with an $R^{2}$ value in all three cases of greater than 0.98 . The theoretical models when fitted to the asymmetric exponential model, have a slightly positive rate difference of $\Delta r \approx 0.02$ year $^{-1}$, which agrees with the statistical analysis of Brandt (2007), who indicated a median rate difference of $\Delta r=0.05$ year $^{-1}$ see Appendix A. for more details. The theoretical models are approximately symmetrical and have $R^{2}$ values of great that 0.95 when compared to Hubbert curves with the same $U R R$ fitted to production data prior to 1979 , with the Ideal case compared to the Hubbert curve having an $R^{2}$ value of 0.995 .

The theoretical model was ammended by use of a technique in Mohr and Evans (2007), to account for the 1979 oil crisis. The method in Mohr and Evans (2007) has four key components: first the original theoretical curve is used to model oil production prior to the anomaly (1979 oil crisis). Second, simple linear or low order polynomials are fitted to the production data from the anomaly to the present day. Three, a polynomial is used to extend the recent production trend, and smoothly rejoin the original theoretical model, in the future. Four, the model returns to the original theoretical model, shifted a certain distance into the future to ensure the area under the graph (URR) is the same. Modifying the theoretical production curve using the literature method in (Mohr and Evans, 2007), allowed for the 1979 oil crisis to be factored, for more details see Appendix D. The amended model is 23 shown in Figure 3 and indicates that the ideal case will peak in 2013, at 13.3 GL/d (83.5 $24 \mathrm{mb} / \mathrm{d})$. The optimistic case peaks in 2025 at $14.1 \mathrm{GL} / \mathrm{d}(88.8 \mathrm{mb} / \mathrm{d})$, and the pessimistic case peaks in 2010 , at $13 \mathrm{GL} / \mathrm{d}(81.8 \mathrm{mb} / \mathrm{d})$.

Whilst the theoretical model matches the data with reasonable accuracy $R^{2}>0.98$, it is important to note several gross simplifications. The assumption that $P_{0}$ and $k_{w}$ are constants 
1 for all wells and reservoirs is too simplistic. Also instead of modeling four US states and

2 using these values to estimate $P_{0}$ and $k_{w}$ it would be better to use a large data set of reservoir

3 data, to determine the average $P_{0}$ and $k_{w}$ for each reservoir, unfortunately such data was not

4 found.

\section{Conclusion}

${ }_{17} C_{p}(t)$ The Cumulative production for the world as a function of time (TL)

${ }_{18} C_{p_{l}}(t)$ The Cumulative production for the reservoir $l$ as a function of time (TL)

${ }_{19} C_{p_{l_{i}}}(t)$ The Cumulative production for the $i$-th well in reservoir $l$ (TL)

${ }_{25} \quad$ The Coefficent of determination (-)

$26 w_{l}(t)$ The number of wells in operation for the reservoir $l$ as a function of time (-) 
$1 \quad y_{d}(t)$ The yearly discoveries function (TL/year)

2 Variables

$3 \quad b_{t} \quad$ The slope constant for the technology function $\left(\right.$ year $^{-1}$ )

$4 \quad k_{1_{i}} \quad$ The proportionality constant relating production to pressure, in the $i$-th well (TL/Pa.year)

$5 \quad k_{2_{i}} \quad$ The proportionality constant relating pressure to remaining reserves ( $\left.\mathrm{Pa} / \mathrm{TL}\right)$

$6 \quad k_{p_{l_{i}}} \quad$ The proportionality constant relating the production to the remaining reserves (year ${ }^{-1}$ )

$k_{w} \quad$ The proportionality constant in the wells model (-)

$k_{w_{l}} \quad$ The proportionality constant for reservoir $l$ in the wells model (-)

$P_{0} \quad$ The initial production of the wells in all reservoirs (TL/year)

$P_{0_{l}} \quad$ The initial production of the wells in reservoir $l$ (TL/year)

$1 \quad P_{l_{l_{i}}} \quad$ The initial production from the $i$-th well in reservoir $l$ (TL/year)

$2 r_{d e c}$ The rate of decrease, as used by Brandt (2007) $\left(\right.$ year $\left.^{-1}\right)$

$r_{\text {inc }} \quad$ The rate of increase, as used by Brandt (2007) $\left(\right.$ year $^{-1}$ )

$\Delta r \quad$ The difference between the rate of increase and rate of decrease, as used by Brandt (2007) $\left(\right.$ year $\left.^{-1}\right)$

$6 \quad$ Time (year)

$17 \quad t_{l} \quad$ The year the $l$-th reservoir is found (year)

$t_{l_{i}} \quad$ The year the $i$-th well comes on-line in reservoir $l$ (year)

$T_{\text {peak }}$ The Peak year for the production curve as used in Brandt (2007) (year)

$T_{\text {start }}$ The start year for the production curve as used in Brandt (2007) (year)

$t_{t} \quad$ The year the technology function reaches 0.5 (year)

URR The Ultimate Recoverable Resources (TL)

${ }_{3} U R R_{l}$ The Ultimately Recoverable Resources for the reservoir l, (TL)

$24 \quad w_{l_{T}} \quad$ The total number of wells for reservoir $l$, if cumulative production was infinite (-)

$25 w_{l_{\text {act }}}$ The total number of wells for reservoir $l$ given the cumulative production is finite

\section{References}

28 Arps, J. j., 1945, Analysis of decline curves: Transactions of AIME, v. 160, p. 228-247. 
1 Aleklett K., 2004, International Energy Agency accepts Peak Oil: ASPO website,

2 http://www.peakoil.net/uhdsg/weo2004/TheUppsalaCode.html (11/27/07).

3 Bakhtiari, A. m. S., 2004, World oil production capacity model suggests output peak by

4 2006-07: Oil and Gas Journal, v. 102, no. 16 p.18-20.

5 Bardi, U., 2005, The mineral economy: A model for the shape of oil production curves:

Energy Policy, v. 33 no. 1 p. 53-61.

Bauquis P., 2003, Reappraisal of energy supply-demand in 2050 shows big role for fossil

8 fuels, nuclear but not for nonnuclear renewables: Oil and Gas Journal, v. 101 no. 7 p. 20-29.

BP., 2006, Statistical Review of World Energy 2006.

Brandt, A. R., 2007, Testing Hubbert: Energy Policy, v. 35 no. 5 p. 3074-3088.

Campbell, C. J. and J. H. Laherrere., 1998, The end of cheap oil: Scientific American, v.

278 no. 3 p. $78-83$.

14 Campbell, C. J., 2003, Industry urged to watch for regular oil production peak, depletion signals: Oil and Gas Journal, v. 101 no. 27 p. 38-45.

16 CAPP, 2006, Statistical Handbook.

7 Deffeyes, K. S., 2002, World's oil production peak reckoned in near future: Oil and Gas Journal, v. 100 no. 46 p. 46-48.

DeGolyer and MacNaughton inc., 2006, 20 ${ }^{\text {th }}$ Century Petroleum Statistics 2005 edition.

Wood, J. H., Long G. R. and Morehouse D. F., 2004, Long-Term World Oil Sup21 ply Scenarios: EIA website, www.eia.doe.gov/pub/oil_gas/petrosystems/petrosysog.html $22(08 / 24 / 07)$.

23 EIA., 2007, Distribution and Production of Oil and Gas Wells by State: EIA website, 24 www.eia.doe.gov/pub/oil_gas/petrosystems/petrosysog.html (08/24/07).

25 Linden H. R., 1998, Flaws seen in resource models behind crisis forecasts for oil supply, 26 price: Oil and Gas Journal, v. 96 no. 52 p. 33-37.

27 Lynch, M. C., 2003, Petroleum resources pessimism debunked in Hubbert model and Hubbert modelers' assessment: Oil and Gas Journal, v. 101 no. 27 p. 38-47. 
1 Mohr, S. H. and G. M. Evans., 2007, Mathematical model forecasts year conventional oil $2 \quad$ will peak: Oil and Gas Journal, v. 105 no. 17 p. 45-50.

3 Moritis, G., 2005, Venezuela plans Orinoco expansions: Oil and Gas Journal, v. 103 no. 43

$4 \quad$ p. $54-56$

5 Reynolds, D. B., 1999, The mineral economy: How prices and costs can falsely signal $6 \quad$ decreasing scarcity: Ecological Economics, v. 31 no. 1 p. 155-166.

7 Wells, P. R. A., 2005, Oil supply challenges - 1: The non-OPEC decline: Oil and Gas 8 Journal, v. 103 no. 7 p. 20-28.

9 Wells, P. R. A., 2005, Oil supply challenges - 2: What can OPEC deliver?: Oil and Gas Journal, v. 103 no. 9 p. 20-30.

11 Williams, B., 2003, Heavy hydrocarbons playing key role in peak-oil debate, future energy 12 supply: Oil and Gas Journal, v. 101 no. 29 p. 20-27. 
1 Appendix A. The rate difference

2 The rate difference, $\Delta r$, as defined by (Brandt, 2007) is

$$
\Delta r=r_{i n c}-r_{d e c},
$$

3 where the rate of increase $r_{i n c}$ and rate of decrease $r_{d e c}$ are determined by fitting Equation A.1 to the 4 production data (Brandt, 2007).

$$
P^{\prime}(t)= \begin{cases}e^{r_{\text {inc }}\left(t-T_{\text {start }}\right)} & \text { if } t \leq T_{\text {peak }} \\ P^{\prime}\left(T_{\text {peak }}\right) e^{-r_{\text {dec }}\left(t-T_{\text {peak }}\right)} & \text { if } t>T_{\text {peak }}\end{cases}
$$

5 where $P^{\prime}(t)$ is production in (barrels/year) and $T_{\text {peak }}$ is the year the production peaks (year) and $r_{\text {inc }}$ and $6 \quad r_{\text {dec }}$ are the rate constants (year ${ }^{-1}$ ) and $T_{\text {start }}$ is the year production was 1 barrel a year Brandt (2007). In 7 calculating the rate difference of the theoretical model equation A.1 was altered to

$$
P^{\prime}(t)= \begin{cases}P(40) e^{r_{\text {inc }}(t-40)} & \text { if } t \leq T_{\text {peak }} \\ P^{\prime}\left(T_{\text {peak }}\right) e^{-r_{\text {dec }}\left(t-T_{\text {peak }}\right)} & \text { if } t>T_{\text {peak }}\end{cases}
$$

where $P(40)$ is the production of oil estimated by the theoretical model in the year 1900 . Using equation A.2 the rate difference for the Pessimistic case was 0.0184 (years $^{-1}$ ), Optimistic case was 0.0179 (years $^{-1}$ ) and the Ideal case was 0.021 (years $^{-1}$ ).

\section{Appendix B. Coefficient of Determination}

2 The coefficient of determination, $R^{2}$, was used to measure the accuracy of the discovery model to the data.

$$
R^{2}=\sum_{n} \frac{\left[y_{f}(n)-\overline{y_{a}}\right]^{2}-\left[y_{f}(n)-y_{a}(n)\right]^{2}}{\left[y_{f}(n)-\overline{y_{a}}\right]^{2}}
$$

For the Pessimistic case $U R R=2$ trillion barrels and for the Optimistic case $U R R=3$ trillion barrels. For the ideal case, the $U R R$ was a variable. The best fit was found by varying $b_{t}, t_{t}$ (and $U R R$ for ideal case) to obtain the highest $R^{2}$ value. The constants are shown in Table B.1. The actual data for the Pessimistic and Optimistic cases was truncated to the year 1966, as the Optimists claim that oil reserves found in the past will grow. 
1 Appendix C. determining the constants

The method to determine valid estimates for the constants $k_{w}, w_{l_{T}}$, and $P_{0}$ in the reservoir production model is given in this section. The best data found is unfortunately state based rather than reservoir based data from EIA (2007). The production model was used with several cycles to model the production as a function of time, and the number of wells as a function of cumulative production for various states as shown in Figures C. $1-$ C. 4 .

\section{Figures C.1 - C.4 hereabouts}

Note our model assumes that no wells are shut down, and instead exponentially decay and although are still on-line, are in reality producing no significant quantity of oil. This is the reason for the poor fit of the well model for Nevada and South Dakota. Now observe that there is only one sensible option for the $w_{l_{T}}$ constants, since these values need to match the actual total wells. The $k_{w}$ values and $P_{0}$ values determine the rate of increase in the wells model and are determined by trial and error so that the wells model and production model fit the data as accurately as possible. Whilst the values used produce reasonably accurate results, we need to check that the initial production values $P_{0}$ correspond to the actual initial production. Unfortunately the initial production for all the wells is not known, however the number of wells as a function of size and time is known EIA (2007) and the model's predictions were compared the actual data for the four states, as shown in Figures C.5 - C.8 (Note that the size of the wells from EIA (2007) is explained in Table C.1)

\section{Table C. 1 hereabouts}

Figures C.5 - C.8 hereabouts

The Figures C.5 - C.8 indicate a reasonable fit and hence the initial well productions $P_{0}$ can be assumed to be reasonable estimates. The constants $k_{w}, P_{0}$ and $w_{l_{T}}$ used in the state models are shown in Table C.2

Table C. 2 hereabouts

Now if we ignore the outlier of 32 for South Dakota, the average for $k_{w}$ is 10.7 and this value is assumed to be constant in the world model; including the outlier the average becomes 12 . By plotting $w_{T}$ versus $U R R_{l} / P_{0}$ we obtained the linear relation $w_{l_{T}}=0.072 U R R_{l} / P_{0}$ which is shown in Figure C.9. The linear relationship is expected, as increasing the size of the reservoir would increase the total number of wells needed. Equally if we have two reservoirs of the same size we could either have a small number of wells with a large initial production $P_{0}$ or a large number of wells with a small initial production $P_{0}$. Hence the linear relationship between $w_{l_{T}}$ and $U R R_{l} / P_{0}$ was expected.

The value for $P_{0}$ appears to have a great deal of variability. However by analyzing the other US state wells sizes from EIA (2007), we observe that Alaska along with Federal Pacific and Federal Gulf, have abnormally large wells compared to the rest of the US, we hence considered the Alaskan well production data 
1 as an outlier and ignored the data. Taking the initial production from Nevada, South Dakota and Alabama, we 2 obtain an average of $18.3 \mathrm{ML} / \mathrm{year}$, which places it in category 16 in the EIA sizes. Hence we assumed that 3 the values of the constants were $P_{0}=18.3$ ML/year, $k_{w}=10.7$ and $w_{l_{T}}=0.072 U R R_{l} / P_{0}$.

\section{Appendix D. Amended model}

6 The amended model $C_{p_{\text {mod }}}(t)$ is determined from the method explained in Mohr and Evans (2007), and

7 formally is:

$$
C_{p_{\text {mod }}}(t)=\left\{\begin{array}{ll}
C_{p}(t) & \text { if } t \leq 118 \\
f_{1}(t) & \text { if } 118<t \leq 123 \\
f_{2}(t) & \text { if } 123<t \leq 129 \\
f_{3}(t) & \text { if } 129<t \leq 145 \\
f_{4}(t) & \text { if } 145<t \leq t_{2} \\
C_{p}\left(t+\left(t_{1}-t_{2}\right)\right) & \text { if } t_{2}<t
\end{array} .\right.
$$

Now $f_{1}(t), f_{2}(t)$ and $f_{3}(t)$ are small polynomials fitted to the production data using least squares 9 method, and formally are:

10

11

$$
\begin{gathered}
f_{1}(t)=-0.82 t+121.7 \\
f_{2}(t)=0.43 t-32.3
\end{gathered}
$$

$$
f_{3}(t)=0.007 t^{2}-1.6 t+109.5
$$

the $f_{4}(t)$ is a $3 \mathrm{rd}$ degree polynomial. The polynomial was determined by the literature method explained generally in Mohr and Evans (2007). Specifically $f_{4}(t)$ is the 3rd degree polynomial such that the following equations are solved:

$$
f_{4}(145)=p(145)
$$

15

16

17

$$
\begin{aligned}
f_{4}^{\prime}(145) & =p^{\prime}(145) \\
f_{4}^{\prime \prime}(145) & =p^{\prime \prime}(145) \\
f_{4}\left(t_{2}\right) & =C_{p}\left(t_{1}\right) \\
f_{4}^{\prime}\left(t_{2}\right) & =C_{p}^{\prime}\left(t_{1}\right) \\
\int_{t_{0}}^{t_{1}} C_{p}(t) d t & =\int_{145}^{t_{2}} p(t) d t .
\end{aligned}
$$


1 Where $t_{0} \approx 138$ and $p(t)$ is a polynomial to replicate the long term historic trend and is $p(t)=-0.004 t^{2}+$

$21.5 t-104.6$. With the list of equations solved, we obtain $t_{1}=153.5, t_{2}=162$ and $f_{4}(t)=-0.0012 t^{3}+$

$30.51 t^{2}-73.4 t+3515.6$ for the ideal case. For the Pessimistic case it was $t_{1}=147.2, t_{2}=153.6$, and

$4 f_{4}(t)=-0.0041 t^{3}+1.77 t^{2}-256.2 t+12353.8 . t_{1}=177.8, t_{2}=196.4$, and $f_{4}(t)=-0.00009 t^{3}+$

$50.036 t^{2}-4.3 t+178.8$ for the optimistic case. 


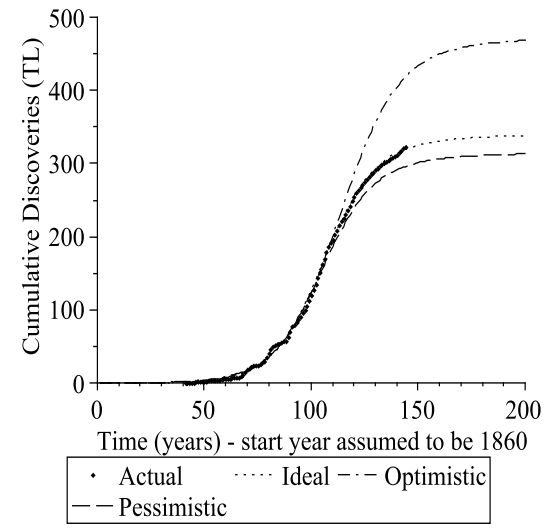

Fig. 1 The modeled cumulative discoveries as a function of time (the year 1860 is assumed as the start year $t=0$.) 
18

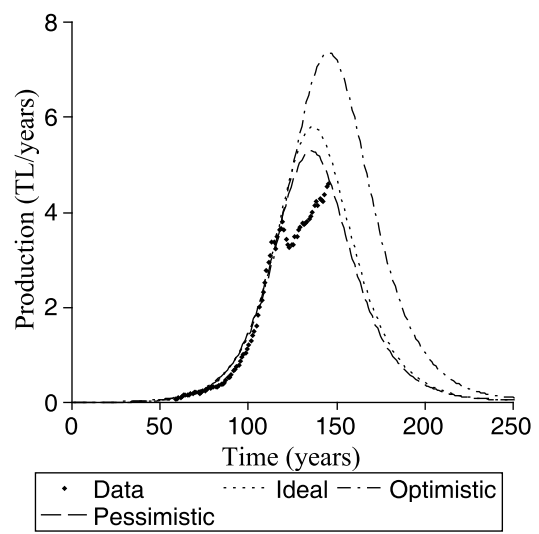

Fig. 2 The production model compared to the actual data 


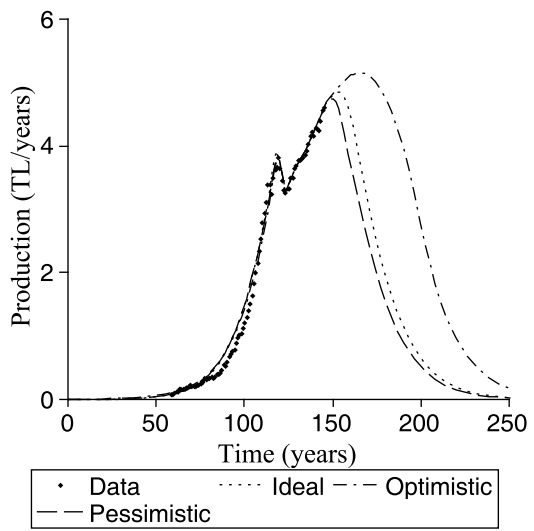

Fig. 3 Results of the modified model compared to the actual production data 
(a)

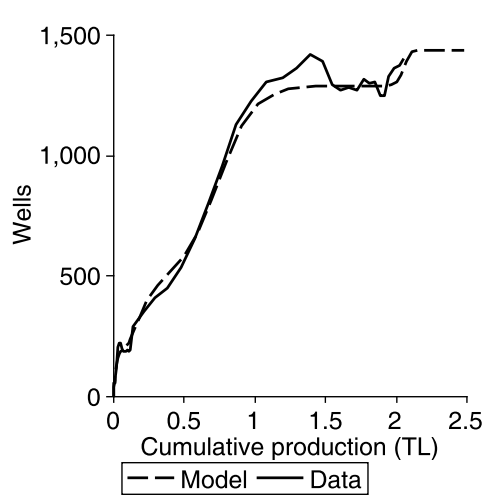

(b)

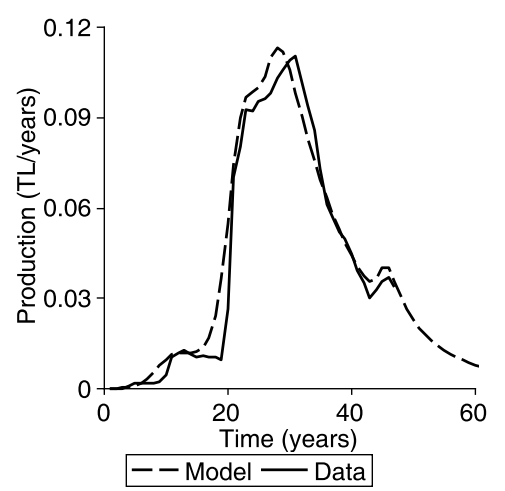

Fig. C.1 a) The number of wells as a function of cumulative production for Alaska and b) Production as a function of time for Alaska 
(a)

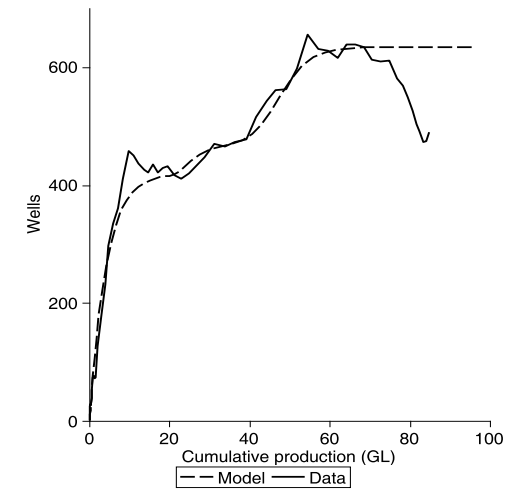

(b)

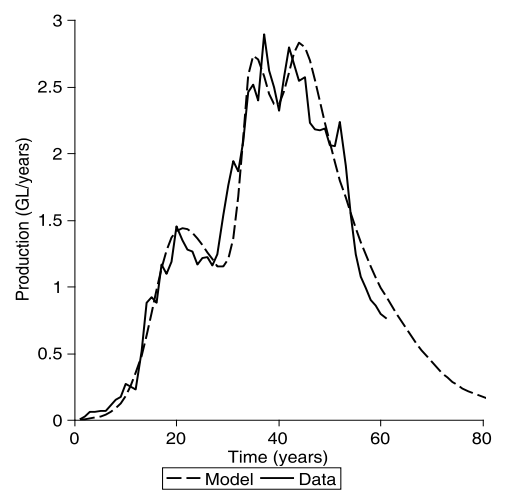

Fig. C.2 a) The number of wells as a function of cumulative production for Alabama and b) Production as a function of time for Alabama 
(a)

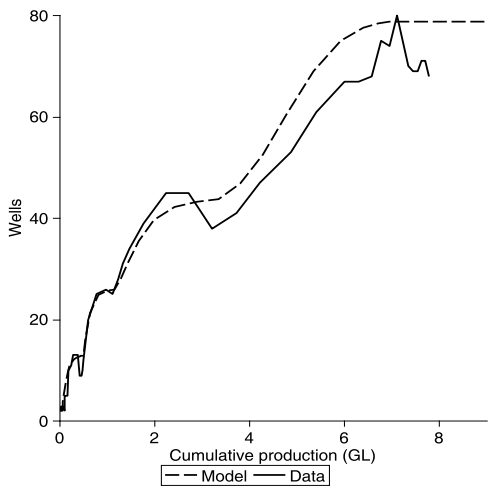

(b)

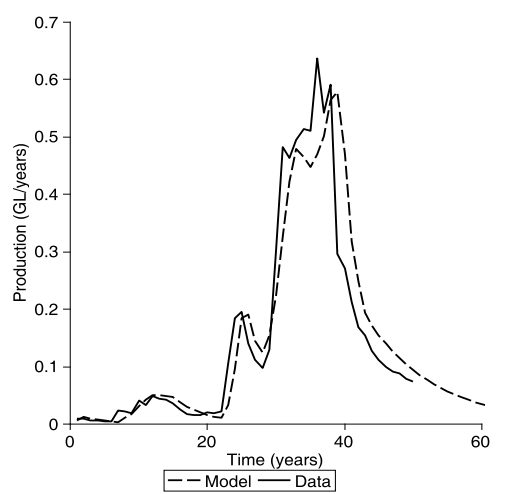

Fig. C.3 a) The number of wells as a function of cumulative production for Nevada and b) Production as a function of time for Nevada 
(a)

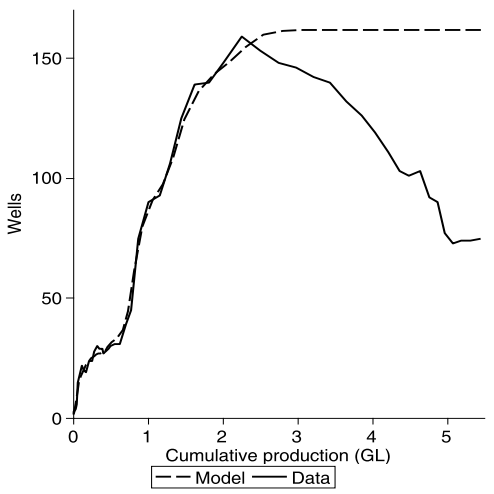

(b)

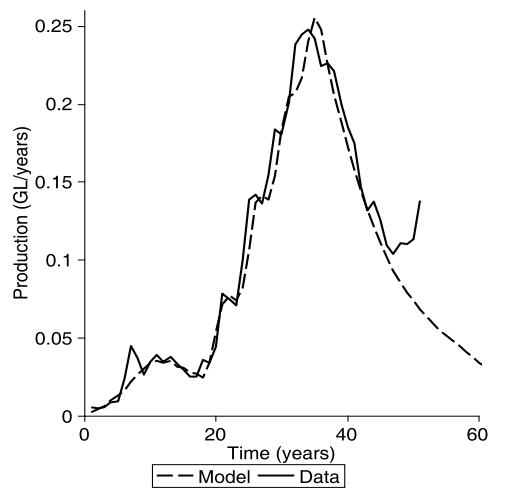

Fig. C.4 a) The number of wells as a function of cumulative production for South Dakota and b) Production as a function of time for South Dakota 
(a)

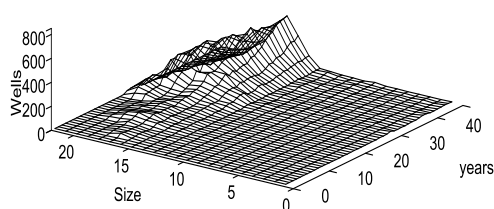

(b)

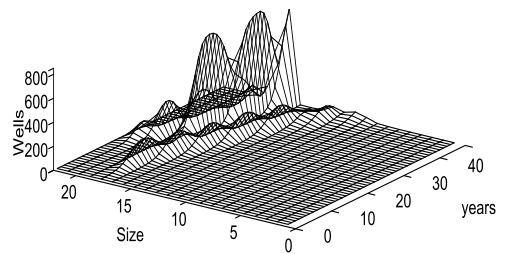

Fig. C.5 The number of wells as a function of size and time for Alaska. a) Actual and b) Model 
(a)

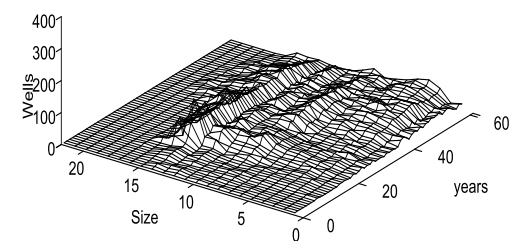

(b)

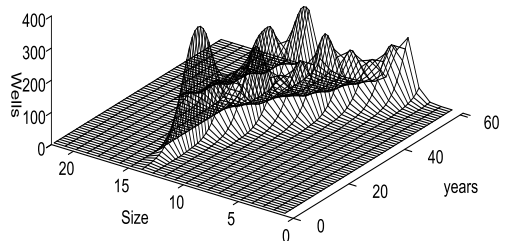

Fig. C.6 The number of wells as a function of size and time for Alabama. a) Actual and b) Model 
(a)

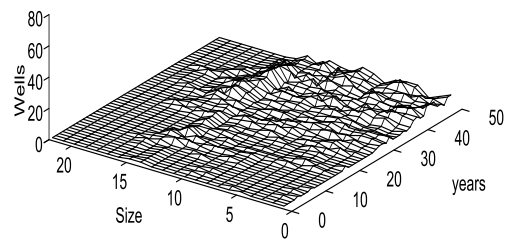

(b)

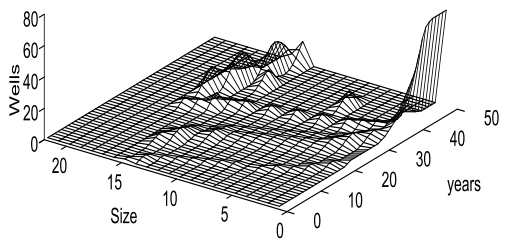

Fig. C.7 The number of wells as a function of size and time for Nevada. a) Actual and b) Model 


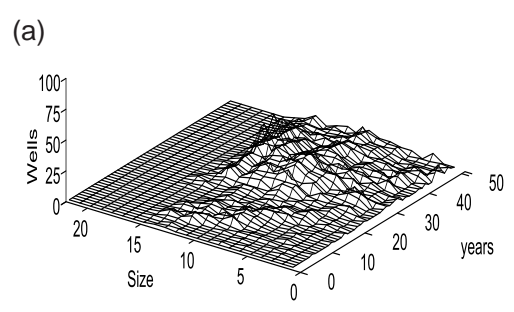

(b)

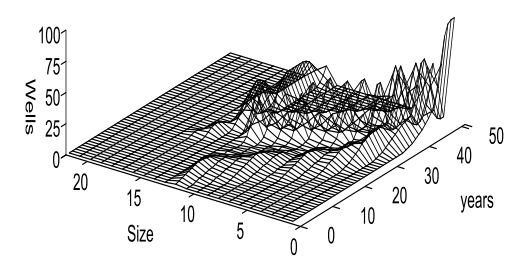

Fig. C.8 The number of wells as a function of size and time for South Dakota. a) Actual and b) Model 


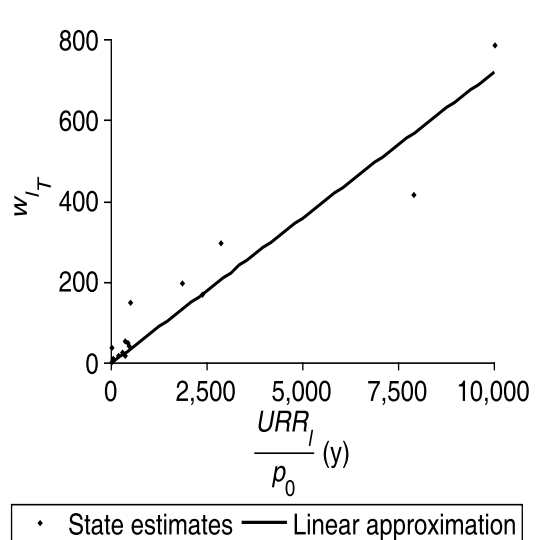

Fig. C.9 $w_{l_{T}}$ versus $U R R_{l} / P_{0}$ 
Table B.1 The $U R R, b_{t}$ and $t_{t}$ for the 3 cases

\begin{tabular}{||l|r|r|r||}
\hline Case & $U R R$ TL (trillion barrels) & $b_{t}$ year $^{-1}$ & $t_{t}$ year \\
\hline Pessimistic & $318(2)$ & 0.0413 & 135.3 \\
\hline Optimistic & $477(3)$ & 0.0372 & 148.9 \\
\hline Ideal & $343(2.16)$ & 0.0421 & 135.4 \\
\hline
\end{tabular}


Table C.1 The size of wells from EIA (2007)

\begin{tabular}{||c|rll||}
\hline Category & \multicolumn{3}{|c||}{ Size barrels/day } \\
\hline 1 & 0 & - & 1 \\
2 & 1 & - & 2 \\
3 & 2 & - & 4 \\
4 & 4 & - & 6 \\
5 & 6 & - & 8 \\
6 & 8 & - & 10 \\
7 & 10 & - & 12 \\
8 & 12 & - & 15 \\
9 & 15 & - & 20 \\
10 & 20 & - & 25 \\
11 & 25 & - & 30 \\
12 & 30 & - & 40 \\
13 & 40 & - & 50 \\
14 & 50 & - & 100 \\
15 & 100 & - & 200 \\
16 & 200 & - & 400 \\
17 & 400 & - & 800 \\
18 & 800 & - & 1600 \\
19 & 1600 & - & 3200 \\
20 & 3200 & - & 6400 \\
21 & 6400 & - & 12800 \\
22 & & $>$ & 12800 \\
\hline
\end{tabular}


Table C.2 The constants for various states

\begin{tabular}{||l|c|r|r|r||}
\hline State & $U R R_{l}(\mathrm{GL})$ & $k_{w}$ & $P_{0} \times 10^{-3}(\mathrm{GL} /$ year $)$ & $w_{l_{T}}$ \\
\hline \multirow{5}{*}{ Alaska } & 174.9 & 9 & 95 & 200 \\
& 1271.9 & 11 & 445 & 300 \\
& 953.9 & 15 & 95 & 790 \\
& 79.5 & 11 & 159 & 150 \\
\hline \multirow{3}{*}{ Alabama } & 41.3 & 10 & 5 & 420 \\
& 27.0 & 15 & 59 & 45 \\
& 30.2 & 13 & 13 & 170 \\
\hline & 0.1 & $-a$ & 8 & 2 \\
Nevada & 0.5 & 5 & 10 & 11 \\
& 0.8 & 7 & 30 & 13 \\
& 6.4 & 14 & 35 & 18 \\
South & 0.8 & 2 & 51 & 39 \\
\hline Dakota & 0.6 & 6 & 2 & 28 \\
& 0.6 & 12 & 13 & 6 \\
& 0.8 & 15 & 2 & 56 \\
& 1.4 & 16 & 3 & 52 \\
& 2.7 & 32 & 8 & 20 \\
\hline
\end{tabular}

${ }^{a} w_{l}(t)=2$ 